\title{
Experience in branding producers-processors of agricultural products to ensure food security in the region
}

\author{
Oksana Shikhova*, Marina Selina, and Olga Barinova \\ Vologda State Dairy Farming Academy named after N.V. Vereshchagin, 160555 Molochnoe village, Vologda region, Russia
}

\begin{abstract}
The article presents the research results of the role and potential of the regional brand, which has united agricultural producers - processers with the aim to solve the problem of quality management of consumer goods and food security governance in the Vologda region. The observed serious demographic problems are connected with the quality and safety of food products as well. The agricultural direction of the economics of the region allows the region to be self-sufficient in quality products of the local producersprocessors. That is why the regional government implements the policy of voluntary certification with the marking "The real Vologda product". This initiative had involved a large number of participants and later became the so named regional trade brand. The analysis of the peculiarities of functioning and development trend of the brand was carried out. The survey results of consumer preferences of the population were presented. They showed the sufficiently high level of trust to the quality and environmental friendliness of the raw material of products by the Vologda producers, in which the brand "The real Vologda product" played an important role. Such technologies of branding are not widely spread in regions. The history and experience of "The real Vologda product" is an example of an efficient tool in the struggle against infringing goods, and of an increase of the level of food security of the population.
\end{abstract}

\section{Introduction}

In the contemporary world, one of the main problems of humanity is food security governance. The interpretations of the essence of the problem are various, but similar in numbers of basic statements. They are:

- safety for human consumption - it is a condition by which there are no following risks: the situations connected with personal injuries and infliction of harm, in case of food safety, connected with causing harm through the food products.

- food safety - it is not only the quality of the food products consumed by the population, but also their quantity sufficient for the optimal provision of biochemical and physiological processes in a human organism necessary for life;

- sanitary and epidemiological safety of food products on all stages starting from the conditions of receiving the raw material and ending with the sale conditions.

With the products of vegetable and animal origin 70 $\%$ of toxins of different nature get into a human organism from the environment [1].

Solving the problem of stable and safe supply of population with food products is important not only in the global level of the world community, but also in the national and regional levels.

The assurance of social stability and population safety is the strategic goal of all developed countries. In achieving this goal the local tasks are solved such as regulation of the situation in the food market, the provision of effectual consumer demand for food, and the fulfillment of support of own agricultural producers [2].

The food safety of the Russian Federation reflects the condition of its economics by which a given level of food independence is ensured [3].

\section{Relevance of the study}

In the furtherance of this problem solution, a question arises, whether the inner economic policy of the region corresponds to the interests of the food market and population demand for quality food products. This research is aimed to the study of inner factors promoting the solution of the problem in the Vologda region.

For today, the achieved level of product production in the AIC (agro-industrial complex) in the geographic area can supply the population of the region with the basic kinds of produced food resourses practically by $100 \%$ (except for meat and vegetables). In particular, the volume of milk production 1.6 times covers the own need in it [4]. It means that the agrarian sector of the area has the potential of product production for other regional markets and abroad. This is an important factor of economic development and solution of the problem of import substitution and food security governance not only in the Vologda region, but also in Russia generally.

The quality of produced and processed products is impossible to ensure without implementation of

Corresponding author: oksana-shikhova@yandex.ru 
contemporary systems of quality and safety management at an enterprise of food and processing industry. This is possible by the way of creating the condition for the development and investment of the brand-technologies in the sphere of agricultural production and processing of raw material [5]. Here the key role is given to the interest of the regional government and its readiness to support such initiatives.

\section{Materials and methods}

The research purpose was in the evaluation of the role of branding the producers-processers of agricultural products in the food security governance in the Vologda region. The research tasks included the study of the inner factors and conditions for the food security governance in the Vologda region; the definition of the role and potential of the regional brand which united the producers-processers of agricultural products within the frame of solving the problem of quality management of consumer goods.

During the research, the following methods of scientific knowledge were used in complex: analysis, synthesis, induction, deduction, the method of statistic analysis, survey of consumer preferences.

The practical significance of the research involves the role definition of the main organizational activity directions of the brand "The real Vologda product" in the solution of the problem with the food security governance and demographic issues of the Vologda region.

The research was carried out in complex, according to several directions requiring the study of the key problems of the area, which had the direct relation to the solution of the problem of the food security governance:

1) the policy of the regional government in relation to perception of relevance and necessity of the solution of the problem of the food security governance and its key directions of implementation;

2) the policy of economy management of producers and processors of products of the agrarian sector, the level of its readiness to participate in the product certification;

3) subjects and directions of realization of quality and safety management of the food products coming into a retail chain, including products of agricultural production;

4) population's behavioral motives for safe consumption of food products from local producers.

The goal of the state policy implemented by the Government of the Vologda region within the frames of promoting the Strategy 2030 of the region development is preserving the region's population [4]. There are many factors of this problem, beginning with the demographic ones and ending with the factors of infrastructure and living standards of people.

The first-priority vital necessity of the population is consumption of food products. Therefore, the creation of a condition for assurance of appropriate quality of food supply, the necessary volume and available price level for food products step forward for government work of all levels as one of the top-priority tasks [6].
To be satisfied with food and be healthy is one of the physiological needs of a human, which he aims to cater foremost. The quality of the food products offered by the retail chain is important for a consumer. It's necessary to know from what raw material and by what producer (reliable or not, from the point of view of environmental safety of the production) the product is made, in what condition the product is transported to a shop, and how the shop adheres to conditions of storage and placement of these products. In fact, besides the presence of food supply it is needed to consider the aspects of its physical and economic availability to the population, and the safety criteria of food products [7]. The human health and the sickness level in the region depend on it. After all, the financial component of a person's possibility to buy the desired food products should not be forgotten. If an income level is not sufficient for qualitatively and safely feeding himself and his own family, then it can become one of the impelling motives to change the place of living and move to the other area.

As you can see, the natural factors of population decline - sickness and mortality - are connected directly to the problem of food safety and quality of food products. Migration factors, appearing as the population outward flow, also directly depend on the level of food safety in the region. The food accessibility in terms of prices and variety, sanitary-epidemiological safety assured by certification of food products, are the important components of living standards of the population. The regional government in full realizes these prime causes of forming demographic problems.

The plan of measures for implementing the strategy of social-economic development of the Vologda region for the period until 2030 and the state programs inprogress are aimed, among other things, to the solution of the food safety problem in the area as well. The decrease in population was mentioned as the main factor limiting the development of the region [8].

Particularly, in the sphere of structural diversification of the regional economy and development of high-tech productions in connection with the agro-industrial and fisheries complexes, the region has the following achievements and competitive advantages relating directly to food security governance:

- sustainable growth of the intensification level in dairy cattle husbandry (cow productivity in agricultural organizations has increased by $52 \%$ within 10 years);

- high availability of product types traditional for the Vologda region: milk and dairy products, eggs, potatoes. Within 5 years the availability of milk and dairy products has increased by $23 \%$, potatoes - by $19 \%$;

- in the last ten years the production volume of the food industry has increased by $22.5 \%$ (in comparable evaluation);

- implementation of the international standards of food safety management systems at the leading enterprises of the food industry;

- output of traditional brand products ("the Vologda butter");

- widening of the production line of food products labeled by the trade mark "the real Vologda product"; 
- possibility of production expansion of food products in the condition of sustainable demand in domestic and external markets for ecologically clean products of the Russian producers of agricultural goods;

- the efficient system of the state support of the development of agricultural sectors (the amount of provided subsidies to producers of agricultural goods of the region increased from 29 subsidy kinds in 2010 up to 50 kinds in 2015) [4].

The key problems and challenges outlined in the Strategy of 2030 and, from our point of view, influencing the solution of the problem of food security governance in the region are:

- inclusion of import (the dependence degree is more than $60 \%$ and the level of sanitary certification of imported products leaves much to be desired);

- the absence of the developed logistic of agricultural products on the territory of the region and the weak development of the system of agricultural cooperation; here, we should add the problem of insufficient development and obligingness of the certification system of agricultural raw material used in processing for the production of food products;

- high competitiveness in agricultural and food markets because of the globalization processes and large retail chains entering the region with their own food lines;

- disparity of prices: producers of agricultural goods have a low level of procurement prices for products (potatoes, vegetables, milk, meat, eggs) for enterprises of food and processing industries and representatives of retail trade in contrast to constantly growing prices of energy commodities and expendable materials;

- undeveloped cooperation of the subjects of agrosector with specialized scientific-research institutions, low "involvement" in the creation process and approbation of innovations, and also in the system of sanitary certification of products;

- the absence of a unified system of regional planning and regulation of production volumes and food product sales, which creates risks of excess of supply over demand and appearance of crisis occurrences in the sectors of agro-industrial complex of the region.

Within the problem solution of the food security governance the important meaning is given to the stimulation of implementation of contemporary quality and safety management systems at enterprises of food and processing industries, and also to the creation of conditions for introduction of ecologically safe technologies in the sphere of agricultural production, storage and processing of raw material.

One of the leading organizations in the Vologda region dealing with implementation of quality and safety management of food products entering the retail chain, including ones of agricultural production, is BI VR "Vologda informative and consulting center of agroindustrial complex" being the right holder of the trade mark (brand) "The real Vologda product".

The Voluntary Certification System "The real Vologda product" was created and registered in the Vologda region at the initiative of the Governor of the region. The main purpose of this project was to show a consum- er that the enterprises participating in the system and the products manufactured by them or a provided service were certified according to its requirements and of consistent high level of quality and safety. The trade mark "The real Vologda product" placed on a package, label or documents indicating the origin of an item of goods or rendering of a service, is the confirmation of this fact [4].

The Voluntary Certification System "The real Vologda product" includes a managing body - BI VR "BI VR "Vologda regional center of quality control", two authorized certification centers and two laboratories. This structure allows rendering services for voluntary certification to any Vologda enterprise which wishes to take part in the system and receive a non-exclusive right of usage of the trade mark "The real Vologda product" on its products.

The trade mark "The real Vologda product" is known far beyond the borders of the region. The mark is given only to certified goods, works and services of responsible economic entities and creates an additional level of protection from penetration of counterfeit, falsified and substandard products [9].

The registration of the symbol "The real Vologda product" as a trade mark is intended to add a legal status to the symbol not only on the territory of the Vologda region, but also in the Russian Federation in general. It provides the opportunity to cut out the abusive practices in relation to the products of the Vologda producers.

The real Vologda product is a quality guarantee of food products, produced by enterprises of agro-industrial complex on the territory of the Vologda region [4].

\section{Results}

The research has shown that brand-technologies provide additional opportunities and allow increasing the efficiency of quality management of agricultural products of own production and food safety on the level of the region.

The successfully developing "The real Vologda product" is the so called umbrella brand which unites different Vologda commodity producers who manufacture products, the quality of which is certified and ensures the problem solution of food safety. This mark guarantees the fact that the product, bearing it, is produced in the Vologda region, and its quality is compliant with the highest international requirements.

The mission, goals and tasks of the trade brand "The real Vologda product" can be presented as the following model (fig.1).

The goal of this trade mark is the possibility to motivate a consumer to acquire quality products, because the permission for the right to use the mark is received by a producer manufacturing food products and industrial raw material, the quality and safety of which are certified.

Food safety issues at the level not only of regions, but of the state generally arise acutely nowadays. Coming-in of counterfeit products causing harm to human health, worsen the standard living of the population of the region and threaten it. The studied regional brand, as the research shows, is capable to solve these problems 
worthily. It's important that keeping-up of population health is carried out by efforts of the local producers.

The Vologda region is one of the first regions in the Russian Federation created and promoting, namely the food trade brand, the mission of which is the assistance in the problem solution of food security governance of the population as well.

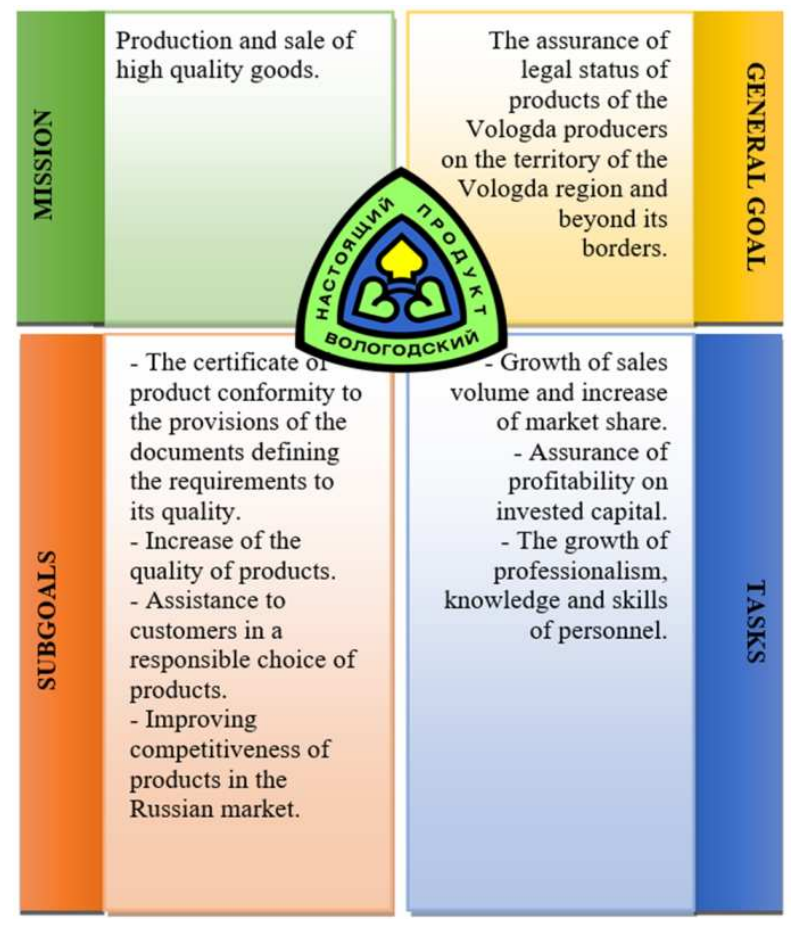

Fig. 1. The model of functioning of the trade brand "The real Vologda product"

A trademark becomes a real brand if it has its history, its loyal consumer [10]. As a result of the high management level and work efficiency of the managing body of the Voluntary certification system represented by BI VR "Vologda regional center of quality control", the number of producers using the brand "The real Vologda product" increases annually (fig.2).

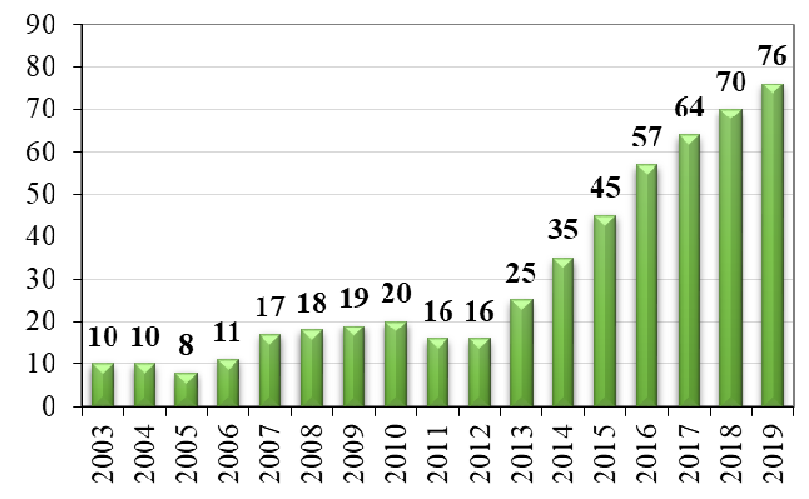

Fig. 2. The number of participants of the Voluntary certification system of BI VR "Vologda regional center of quality control" [11]

The results of the analysis show that the most notable growth in the amount of the brand participants has been observed since 2014. This is explained by sanctions against Russia. Consequently, they lead to a necessity of import substitution of many products of agricultural origin [12].

The regional plan for import substitution of the Vologda region for the period of 2016-2020 has been successfully implemented [4]. Shops and shopping units which have joined the program of the plan measures and have the right to use the trade mark "The real Vologda product" are spread through the districts of the Vologda region. They also exist the Leningrad, Arkhangelsk, Ryazan, Novgorod, Ivanovo and other regions, the Republics of Karelia and Komi, and such cities as Moscow, Saint Petersburg, Velikiy Novgorod, Ryazan. This promotes to the problem solution of import substitution and food safety in the other regions of the country (fig. 3 ).

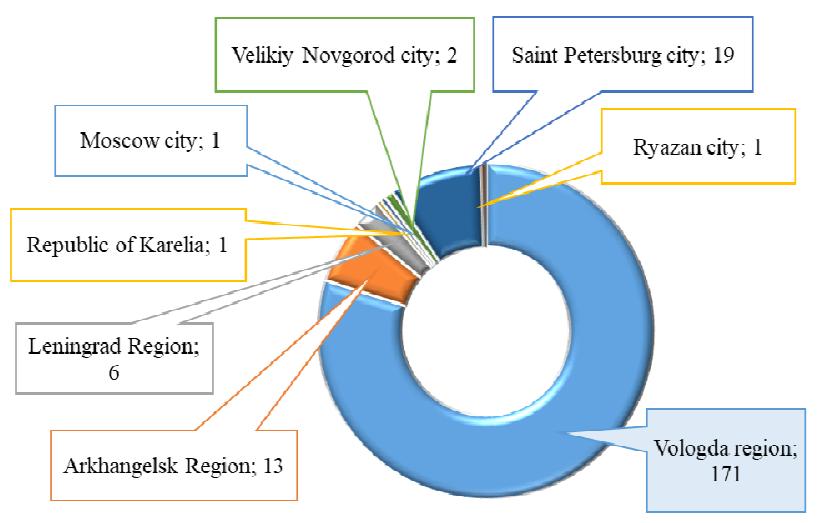

Fig. 3. The number of brand shopping units representing the products of "The real Vologda product" in the regions of the $\mathrm{RF}$ as of 31.12.2019

Besides, the promotion of the brand is aimed to foreign countries. Thus, under the trade mark mentioned above, the products are supplied abroad, including to non-CIS countries: Estonia, the Ukraine, Kazakhstan, the USA, Germany, Israel, France, Canada, Finland, China and others.

Considering the structure of unity of brand participants, enterprises and individual entrepreneurs which participate in the Voluntary certificate system, organized by BI VR "Vologda regional center of quality control", we can see what food products and industrial raw material produced on the territory of the Vologda region. It is worth mentioning that all the main sectors for meeting the current consumer needs of the population are represented in it (fig.4).

Provision of food safety to the population is possible by two ways actually: either to produce raw material and food products by own efforts controlling the quality of all processes of this production (from the agricultural enterprise to a shop shelf), or to supervise the quality of imported products strictly. The first way is indeed realistic for the Vologda region, thanks to the successful functioning of the Voluntary certification system. The region in relation to the production volumes of agricultural products is capable to be practically in full selfsufficiency. It is very important so that the coverage of the local processors of products of the agrarian sector by 
the system of quality management will be as wide as possible. To this day, for middle, small and micro enterprises involved in the processing of agricultural products and producing drinks and food products, the share of participation in the Voluntary certificate system makes about $33 \%$.

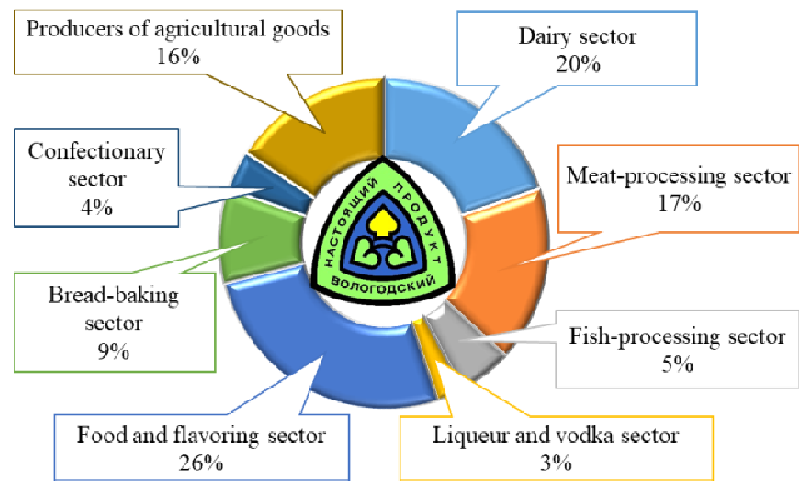

Fig. 4. The sectoral structure of the producers-participants of the trade brand "The real Vologda product" in 2019

The results of the research of consumer preferences show that not less than a half of surveyed population pay attention to the quality of acquirable food products and about one third study the information on a package. Owing to the high quality and ecological safety of raw material for products of the Vologda producers, which are already famous far beyond the borders of the region, the consumers' trust exactly to the products of own regional production grows annually. The brand "The real Vologda product", the trademark of which is placed on most of exported food products, plays an important role in this.

Thus, despite the variety of dairy products on the shelves of shopping units in relation to the producers more than $70 \%$ of the population chooses exclusively the Vologda region production and $23 \%$ largely prefer local producers. The indexes relating to consumer preferences for meat products are slightly lower: sausage $-49 \%$ and $38 \%$, poultry meat $40 \%$ and $43 \%$ respectively (fig. 5).

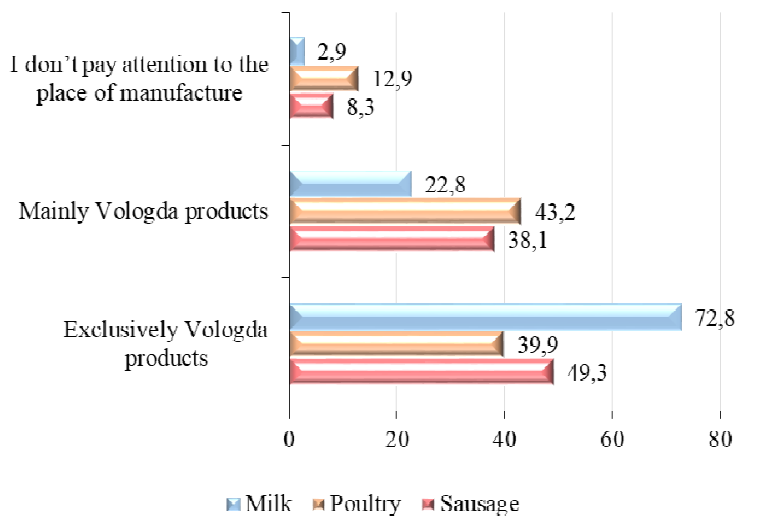

Fig. 5. The results of the survey of the Vologda region population about preferences in relation to the producers of consumable products, in percent
The further development and improvement of the quality management system of agricultural products of own production has significant importance both in the formation of the economic potential of the region and in the strengthening of the population trust to the products of the local producers.

Thanks to the active promotion of the brand "The real Vologda product", the reputation and economic condition of the Vologda region have been created and are strengthened annually. The important strategy directions of the region development are implemented, such as step up in exports of products and reduction in consumption of imported food commodities and goods of third party products. That allows increasing the share of the products of the guaranteed safe quality in the regional consumer market.

\section{Conclusion}

The research has shown that the specified problem of food security governance in the area is paid constant attention to by the government of the Vologda region and is being actively solved owing to the Voluntary certification system, the development and strengthening of the position of the trade brand "The real Vologda product". The special emphasis should be given to the competitive advantages of the area in relation to the system of measures implemented for the food security governance and the reviewed experience of the regional authorities for the certification of food products and the usage of the branding technology through the example of creation and development of a trade brand. In our opinion, the usage of the branding technology helps the regional authorities to straggle with counterfeit products, to increase the level of food safety, to sustain a positive image of the region and support its economic welfare. All these promote the improvement of living standards and consequently solve the demographic problem of the people saving.

The article is prepared with the financial support of the Government of the Vologda region within the state scientific grant "The approaches to the evaluation of the brand power and rating of commodity producers of the Vologda region, Russia as viewed by consumers".

\section{References}

1. A. Alimov, T.Yakupov, F. Zinnatov, N. Kasanova, The safety of food raw material and food products, In the book: The safety of food raw material and food products (Kazan, 2019)

2. O. Moronova, A. Dorogovtsev, Investigation of food supply in the Vologda region, Economic and social changes: facts, trends, forecast, 1 (2010)

3. V. Selin, Methodological aspects of analyzing and assessing the per capita consumption of fish and seafood in the Russian Federation, Economic and Social Changes: Facts, Trends, Forecast, 6 (2015) 
4. On approval of the regional plan for import substitution in the Vologda region for the period of 2016-2020 http://docs.cntd.ru/document/444707503

5. V. Selyukov, N. Shalygina, The use of brandtechnologies in the agricultural sector of the region, Modern problems of science and education, 5 (2014)

6. A. Chekavinskiy, R. Selimenkov, Modeling of food security in the region, Economic and Social Changes: Facts, Trends, Forecast, 4 (2014)

7. O. Shikhova, M. Selina, V. Selin, Application of methods of modeling and forecasting for planning of operating results of fish processing enterprises, $\mathrm{BIO}$ Web of Conferences, 17, 00157 (2020)

8. About the strategy of social-economic development of the Vologda region for the period until 2030 http://vologda-

oblast.ru/upload/iblock/cfe/strategiya2030.pdf
9. E. Safargaliev, The components of a trade brand, Regional Economics: Theory and Practice, 31(262) (2012)

10. K. Averchenko, Positioning and promotion of industrial brand in the market of final consumers, Marketing management of an enterprise, 3 (2017)

11. O. Burgomistrova, Regional brands "The Vologda butter", "The real Vologda product", AgroZooTechnics, 1, 4 (2018)

12. T. Yureneva, O. Barinova, S. Golubeva, Monitoring of the financial condition of agricultural organizations in the Vologda region of Russia, Towards Productive, Sustainable and Resilient Global Agriculture and Food Systems: Conference proceedings (2018) 